\title{
Determination of Bingham Parameters of Fresh Portland Cement Concrete Using Concrete Shear Box
}

\author{
S. Girish and B.S. Santhosh
}

\begin{abstract}
The workability of fresh concrete should be characterized by its rheological properties based on material science approach to overcome the inadequacies of traditional empirical tests like slump test. Generally the rheological properties of fresh concrete are described by Bingham parameters in terms of two physical quantities, namely yield stress and plastic viscosity. Rheometers are used to find the two rheological parameters, which use high speed torque to shear the concrete and the stimulus provided during testing is dynamic. But, there is no concurrence in the measurement of rheological values by various rheometers.

In this systematic study the Bingham parameters of normal concrete was found from using a specially fabricated new concrete shear box. The advantage of this test is the low shear rate applied on the specimen during testing which is similar to the condition the fresh concrete experiences in the field and the static condition of the test. The procedure is unique in that, after finding the peak shear stress, shear stress at zero normal stress and at zero displacement were found and finally finding the Bingham parameters. The water was varied from 160 to $190 \mathrm{l} / \mathrm{m}^{3}$ and cement content from 300 to $450 \mathrm{~kg} / \mathrm{m}^{3}$. Different displacement rates (5 to $25 \mathrm{~mm} / \mathrm{min}$ ) and normal stresses (0.015 to $\left.0.035 \mathrm{~N} / \mathrm{mm}^{2}\right)$ were used. Total number of tests considered was 324 and the mixes were prepared with and without Superplasticizer. The results show that the concrete shear box can be used as a new tool to measure the relative values of yield stress and plastic viscosity of fresh concrete effectively as a static test, with low shear rate. The values are higher but the trends are very similar to the studies using rheometers.
\end{abstract}

Keywords--- Rheology, Yield Stress, Plastic Viscosity, Rheometers, Concrete Shear Box

\section{INTRODUCTION}

$\mathrm{T}$ HE concrete behavior is complex and workability of fresh concrete is a critical property that has a direct impact on the strength, durability, appearance and cost. The technology to measure the workability of concrete has not changed significantly in the last century and is still being measured using the simplistic test method the slump test, inspite of its

S. Girish, Professor, Department of Civil Engineering, B.M.S. College of Engineering, Bangalore, India. E-mail: giris41@yahoo.co.in and girish.civ@bmsce.ac.in

B. S. Santhosh, Assistant Professor, Department of Civil Engineering, JSS Academy of Technical Education, Bangalore, India. E-mail: santhoshbss@gmail.com

DOI: 10.9756/BIJIEMS.1620 deficiency in correctly differentiating a mix. In fact, concrete with the same slump may flow differently and may have different workability and as such concrete flow cannot be defined by a single parameter [1].

Rheology is a well established study of deformation and flow of materials under loads and fluid rheology is a widely used science. Many fluids possess some minimum stressnamely a yield stress-that must be exceeded before flow occurs. Flocculated systems such as cement pastes typically are thixotropic and exhibit a yield stress. The concept of yield stress is readily seen in concrete slump test though it is an empirical test. Even though fresh concrete can be considered a fluid, the characterization of its rheology is complicated by the fact that concrete is a complex heterogeneous material with time-dependent properties. However, workability of a fresh concrete mixture is closely related to the flow properties of the concrete and there is a need to develop methods based on a material science approach especially with the advent of special concretes and finding rheological properties of fresh concrete will always remain the focus of the concrete industry. Various models or constitutive equations have been developed to characterize the flow of concrete. Freshly mixed concrete can be considered as a concentrated suspension of aggregates in cement paste and can be measured as a viscous or viscoelastic fluid and is based on the relationship between shear stress $(\tau)$ and shear rate $(\gamma)$ expressed as a flow curve. Most researchers agree that the flow of concrete can be described reasonably well using a Bingham equation. This equation is a linear function of the shear stress (the concrete response) versus shear rate. Two parameters provided by the Bingham equation are the yield stress and the plastic viscosity. Compared to a Newtonian model, the Bingham model incorporates a yield stress term $\tau_{0}$ and the viscosity is often replaced with plastic viscosity $(\mu)$. It describes a linear relationship between the stress acting to shear concrete (shear stress $=\tau$ ) and the rate at which it is sheared (shear rate $=\gamma$ ) with plastic viscosity $(\mu)$ being the slope in this relationship and the y intercept marks the yield stress $\left(\tau_{0}\right)$ and the relation is as follows:

$$
\tau=\tau_{0+} \mu \gamma
$$

The term yield stress and plastic viscosity provides a more comprehensive description of fresh concrete than the conventional workability tools. Static measurement of yield stress measured when the material is initially at rest are typically higher than the measurements of yield stress obtained from dynamic measurements of the flow curves. Bingham flow model commonly assumes that if lower shear rates could be measured the flow curves would continue back 
and intercept shear stress axis [2]. Accurate data at low shear rates are needed to confirm that flow curves can truly be extrapolated to a zero shear rate. The advent of modern controlled stress rheometers have allowed measurements to be made at significantly lower shear rates than previously possible. These rheometers show that at low shear rates, plastic viscosity is very high. Ngugen and Boger [3] state that yield stress is a model parameter but not a true material property. If it is assumed that yield stress is a relevant parameter to be measured, the actual measured value can vary significantly depending upon the test method used. Rheology is now seriously considered by users, rather than being seen as an inconvenient and rather specialized branch of cement science [4]. By providing a scientific description of the fundamental flow properties of cement paste, mortar and concrete, rheology represents a useful method of characterizing concrete workability.

This study initially outlines the measurement of flow properties of fresh concrete using Bingham equation and describes the drawbacks of dynamic tests using rheometers and then describes a unique new procedure for the determination of rheological properties of concrete from an extensive study of the experimental data obtained using a newly designed and fabricated concrete shear box. The uniqueness of the procedure is that after finding the peak shear stress, shear stress at zero normal stress and zero displacement were found, and finally finding the Bingham parameters. This complete procedure is first of its kind, hitherto, not attempted previously. The importance of the test is very much significant in that concrete specimen is subjected to a low shear rate during testing which is similar to that experienced by the concrete in the field and the static condition of the test. For the experiments, workable concrete mixtures for varying w/c ratios, different normal stresses and displacement rates were considered.

\section{RHEOMETERS}

In concrete, rotational rheometers are used predominately in cases where the rheological parameters are to be determined in fundamental units while variations on capillary tube viscometers are used in limited cases. Rotational rheometers for concrete typically feature one of the three geometrical configurations - coaxial cylinder, parallel plate and impeller. Coaxial cylinder rheometers consist of two cylinders with one cylinder rotating relative to the other. The variation in shear stress and shear rate can be calculated across the horizontal gap based on measurements of torque at various rotation speeds. Parallel plate rheometers which consist of two horizontal plates with one plate rotating relative to the other permit a small specimen size and the direct analytical calculation of rheological parameters. In impeller rheometers an impeller is rotated in a concrete specimen. Rotational rheometers continuously apply shear to a fluid specimen through rotational movement and provide measurements of shear stress and shear rate. According to Hackley and Ferraris [5], rotational methods are generally better for concentrated suspensions, gels and pastes despite the fact that capillary tube methods tend to be more precise in measuring plastic viscosity. Rotational methods offer the advantage of being able to shear a sample continuously in order to achieve equilibrium and to monitor changes over time. They are basically dynamic tests.

While traditionally rheometers have been successfully used for fine particle suspensions, concrete presents unique challenges. Rotational rheometers are most typically used exclusively in the laboratory. Although some rotational rheometers have been designed to be sufficiently small and rugged for use on jobsites, the limited availability and high cost of these devices make them impractical for regular field use. The range of shear rates applied in a rheometer for a given fluid should be similar to the shear rates present in an actual field condition, but this does not happen in most rheometers. Not many studies seem to have been done to determine the actual shear rates in the field for different construction processes. The values of yield stress and plastic viscosity compiled by Ferraris et. al., [6] from different rheometers, but measured on identical concrete mixtures show that there is no agreement of the measured values among the different types of Rheometers.

\section{DIRECT SHEAR BOX}

The shear box test is the oldest and simplest form of shear test arrangement. Basically, the testing procedure is very straight forward. The test has been used for measuring the 'immediate' or short-term shear strength in terms of total stresses. In principle, the shear box is an 'angle of friction' test, in which one portion of specimen is made to slide along another by the action of steadily increasing horizontal shearing force while a constant load is applied normal to the plane of relative movement. As reported by Newman [7], Herschel and Pisapia and later L'Hermite and his coworkers used direct shearing apparatus of the kind used for testing the strength of soils to study the resistance of freshly mixed concrete in terms of shear stress. They considered shearing stress in a freshly mixed concrete to be due to internal friction analogous to the friction between a solid body and a plane solid surface when that body is resting on the surface. When they plotted the graphs between shear stress verses shear strain for various normal stresses, keeping the displacement rate constant, interestingly they found that shear stress increases linearly with the degree of distortion upto a maximum value, then decreases and finally leveling off. This was called as 'dilatancy' and the reason for this decrease in shear resistance was that after this stage, further distortion resulted in the formation of a sliding plane and the coarse particles originally interlocked take up positions with less resistance to movement. So, in a direct shear test apparatus, the shearing stress is created by imposing a movement of the lower half of the shear box while applying a static load to the load plunger and can be used to assess the cohesive strength of a fresh concrete mixture under the influence of normal stress and displacement.

\section{EXPERIMENTAL PROGRAMME}

\subsection{Materials}

Ordinary Portland cement (C 53 grade), conforming to the requirements of Indian standard IS 12269-1987(ASTM C 150- 
$85 \mathrm{~A})$ was used. The specific gravity value and Blaine fineness were 3.15 and $265 \mathrm{~m}^{2} / \mathrm{kg}$. Natural river sand was used as fine aggregate and crushed angular granite stone as coarse aggregate. The bulk specific gravities of the coarse aggregate and fine aggregate were 2.68 and 2.67 respectively and their absorption values were 0.35 and $2 \%$ respectively. The maximum size of the aggregate used was $20 \mathrm{~mm}$. Commercially available Polycarboxylic ether based Superplasticizer (Glenium B233) was used as chemical admixture. The product had specific gravity of 1.09 and solid content not less than $30 \%$ by weight.

\subsection{Methodology}

In this study, mixes with three different cement contents of 300,390 and $450 \mathrm{~kg} / \mathrm{m}^{3}$ and water contents of 160,175 and $190 \mathrm{lt} / \mathrm{m}^{3}$ were used. The range of $\mathrm{w} / \mathrm{c}$ ratio covered was from 0.35 to 0.63 practically the wide range used in practice. The concrete mixes were proportioned based on absolute volume concept. Total of 324 trials consisting of three different strain rates of $5,15,25 \mathrm{~mm} / \mathrm{min}$, in combinations with three different normal stresses of $0.015,0.025,0.035 \mathrm{~N} / \mathrm{mm}^{2}$, were used. To know the effect of using chemical admixture, tests were done with and without using chemical admixture and for the mixes with chemical admixture the dosage was kept constant at $1 \%$. After through mixing of the fresh concrete in a pan mixer the sample was tested for measuring the rheological properties such as yield stress and plastic viscosity.

\subsection{Concrete Shear Box}

Based on the experience from the previous test results obtained [8] from using the smaller size direct shear box $(60 \times 60 \times 25 \mathrm{~mm})$ and the unique procedure adopted for obtaining rheological parameters for static loading condition, a new customized fabricated concrete shear box was used for testing fresh concrete in this study. The new test apparatus works on the principles of direct shear box with modified features that are essentially needed to shear the sample of fresh concrete at different rates. This new tool is first of its kind for testing the fresh concrete sample. The strain rate to shear ranges from $1 \mathrm{~mm} / \mathrm{min}$ to $100 \mathrm{~mm} / \mathrm{min}$. The shear stress developed at such a faster rates is captured using servocontrolled data acquisition system. The loading unit has different normal stresses up to maximum of $30 \mathrm{~N} / \mathrm{mm}^{2}$. The size of the sample was $150 \mathrm{~mm}$ cube and can be tested for coarse aggregate of maximum size $25 \mathrm{~mm}$. The normal loads are applied on the specimen through a pneumatic actuator and a stress regulator. Electronic data acquisition system is used for acquiring the data and storing it to computer. Figure 1 show the newly fabricated concrete shear box used in this study. The important characteristics of this test are the static condition of the test and very low shear rate applied on the specimen during testing which is similar to the condition experienced by the concrete in the field.

\subsection{Procedure for the Determination of Rheological Properties}

The detailed procedure to determine the Bingham parameters using Concrete shear box for the first time has been published by the authors elsewhere $[9,10]$. This section briefly illustrates the procedure once again for the benefit of the readers for one of the mix (says Mix G) considered in this study. The freshly mixed concrete was placed in the concrete shear box and a particular displacement rate $(\gamma)$ and a normal stress was applied on the sample. The test was stopped when the shear load started to decrease (point of dilatancy) or when it became almost constant. The tests were repeated for different displacement rates keeping the normal stress constant. For the displacement rates chosen further tests were conducted for different normal stresses.

One such plot for the mix $(G)$ is shown in Figure 2. The plot of shear stress verses shear strain for displacement rate of $5 \mathrm{~mm} / \mathrm{min}$ for normal stress of $0.015 \mathrm{~N} / \mathrm{mm}^{2}$ is shown in Figure 2(a). From this relation the maximum shear stress ( $\left.\zeta^{\prime}\right)$ for the normal stress $0.015 \mathrm{~N} / \mathrm{mm}^{2}$ was found. For the same normal stress, similar procedure was followed for the mix for finding the maximum shear stress with the displacement rates of 15 and $25 \mathrm{~mm} / \mathrm{min}$ and the plots are shown in Figure 2 (b) and 2(c). Similar plots of shear stress verses shear strain for the displacement rates of 5,15 and $25 \mathrm{~mm} / \mathrm{min}$ were obtained for other normal stresses 0.025 and $0.035 \mathrm{~N} / \mathrm{mm}^{2}$.
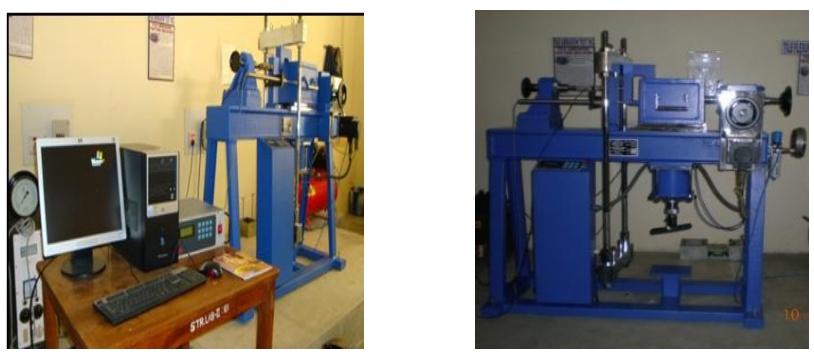

Figure 1: Concrete Shear Box

These plots are shown in Figures 2 (d) to 2 (i) and maximum shear stresses were obtained. Further, with the values of maximum shear stress for each displacement rate and the different normal stresses, graphs are plotted and straight line fits were made (Figure 3$)$. The line intersecting the y-axis (shear stress axis) gives the peak shear stress ( $\zeta{ }^{\prime}$ o of concrete at zero normal stress for a particular displacement rate, as the concrete shear box test cannot be carried out at a zero normal stress. Similar straight line fits were made for all displacement rates and peak shear stress at zero normal stresses were obtained. This peak shear stress can be considered as yield stress at zero normal stress. Further, graph was plotted between displacement rates and the yield stress at zero normal stress obtained for different displacement rates (Figure 4). The intercept of the line on the y-axis $(\zeta$, yield stress axis) can be regarded as the relative yield stress $\left(\zeta_{0}\right)$ and the slope of this line as the relative plastic viscosity $(\mu)$ similar to Bingham parameters [11].

The uniqueness of this test method is that, the shear stress at zero normal stress and zero displacement was found, before finally finding both the relative yield stress and the relative plastic viscosity. Other important characteristics of this test are the very low shear rate applied on the specimen during testing which is similar to the condition experienced by the concrete in the field and also the static condition of the test. 


\section{RESUlts AND Discussion}

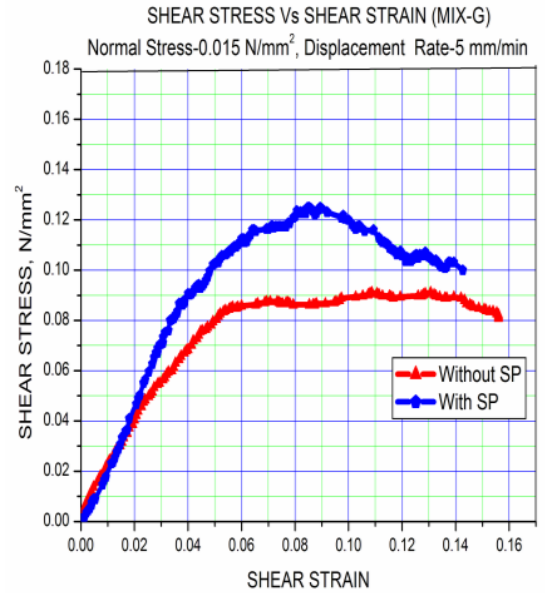

Figure 2(a): Shear Stress Vs Shear Strain (Disp. Rate-5mm/min)

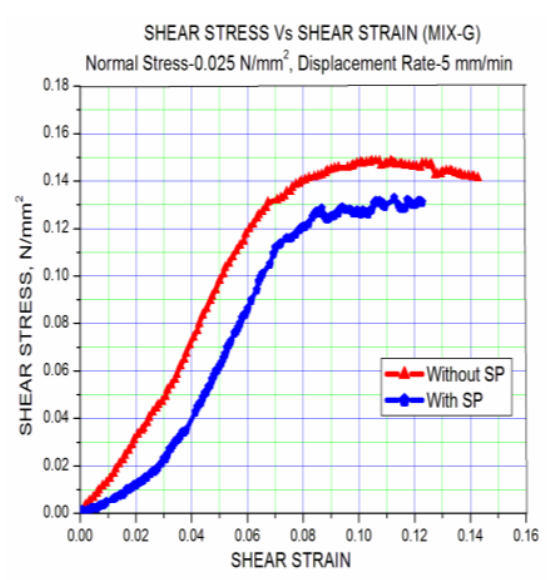

Figure 2(d): Shear Stress Vs Shear Strain (Disp. Rate- $5 \mathrm{~mm} / \mathrm{min}$ )

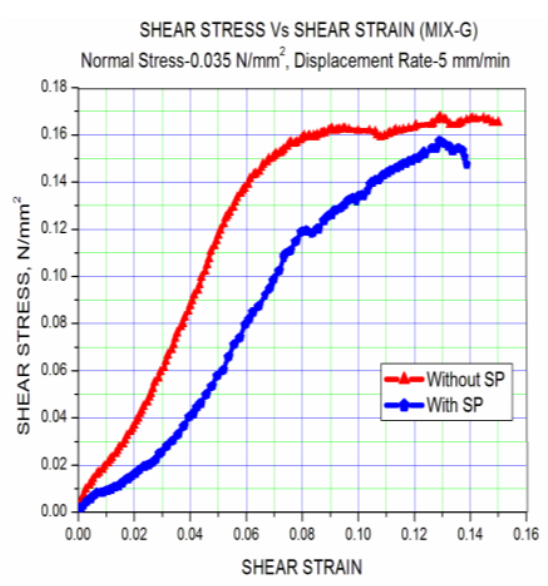

Figure 2(g): Shear Stress Vs Shear Strain (Disp. Rate-5mm/min)

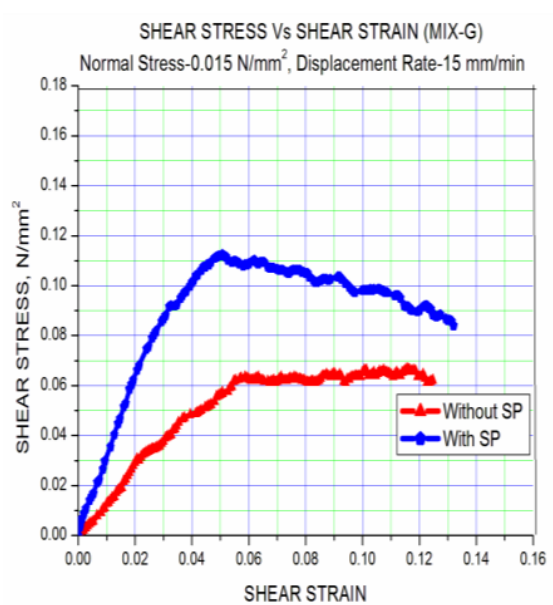

Figure 2(b): Shear Stress Vs Shear Strain (Disp. Rate-15mm/min)

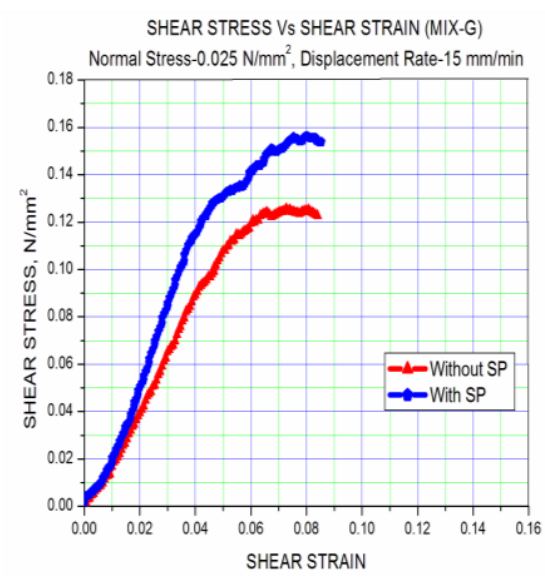

Figure 2(e): Shear Stress Vs Shear Strain (Disp. Rate-15mm/min)

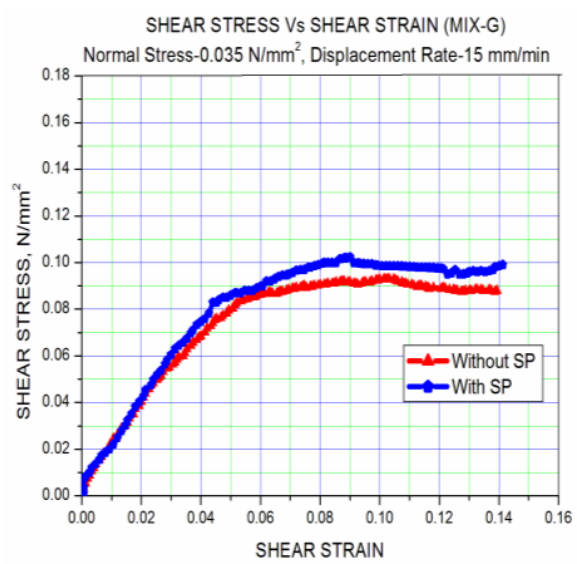

Figure 2(h): Shear Stress Vs Shear Strain (Disp. Rate-15mm/min)

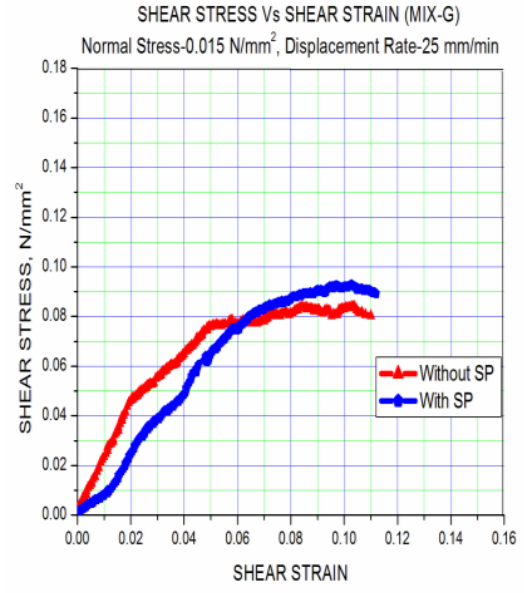

Figure 2(c): Shear Stress Vs Shear Strain (Disp. Rate-25mm/min)

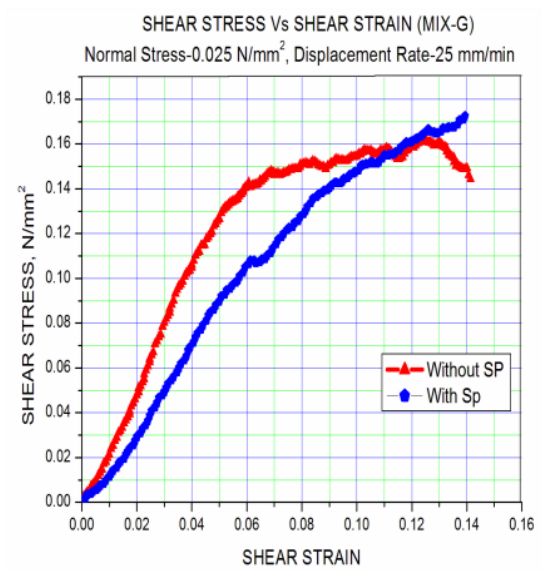

Figure 2(f): Shear Stress Vs Shear Strain (Disp. Rate-25mm/min)

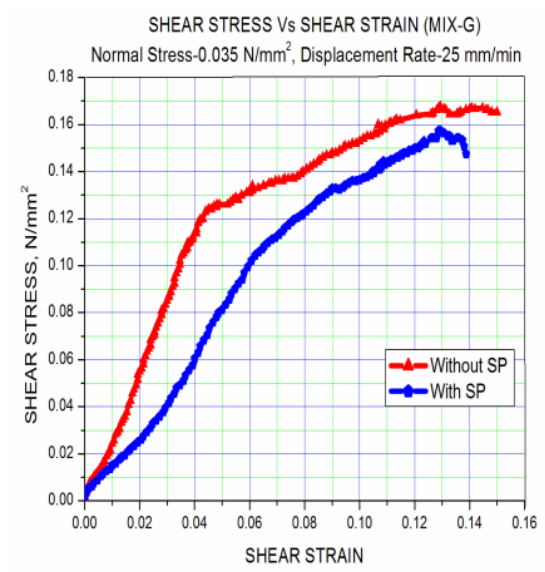

Figure 2(i): Shear Stress Vs Shear Strain (Disp. Rate-25mm/min)

Figure 2: Shear Stress Vs Shear Strain 

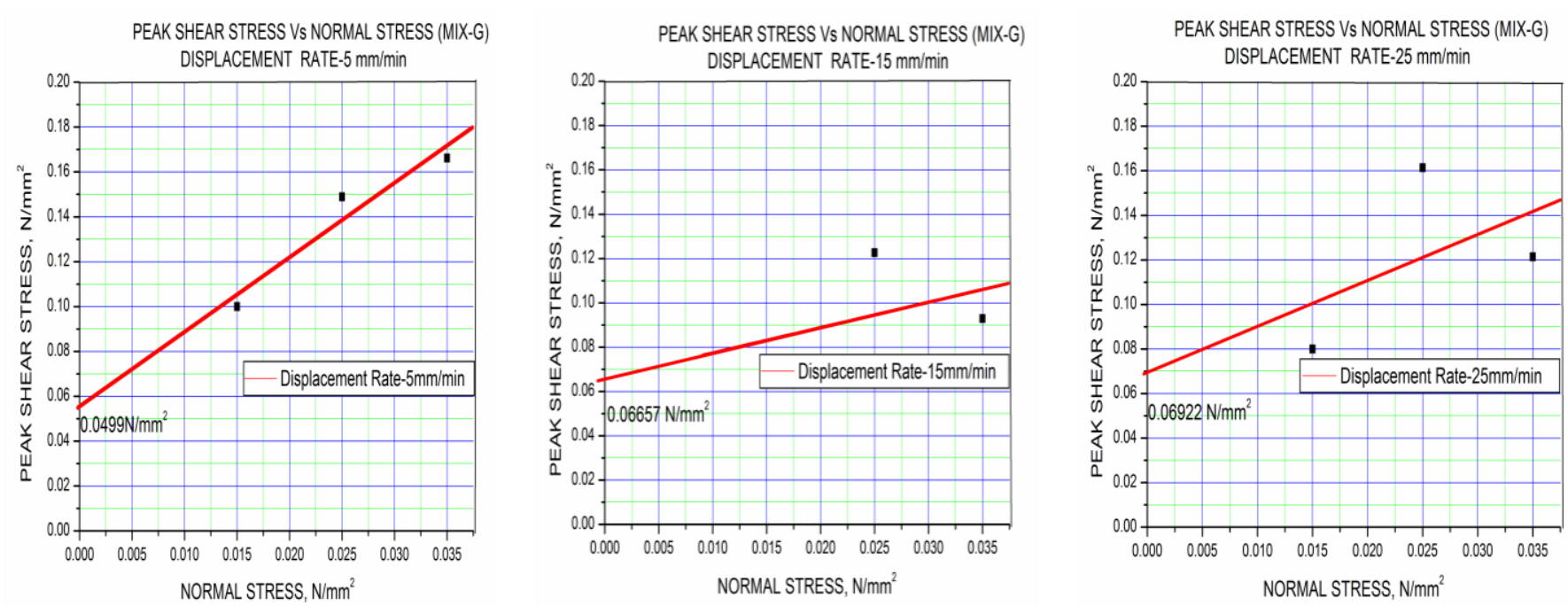

Figure 3: Peak Shear Stress Vs Normal Stress

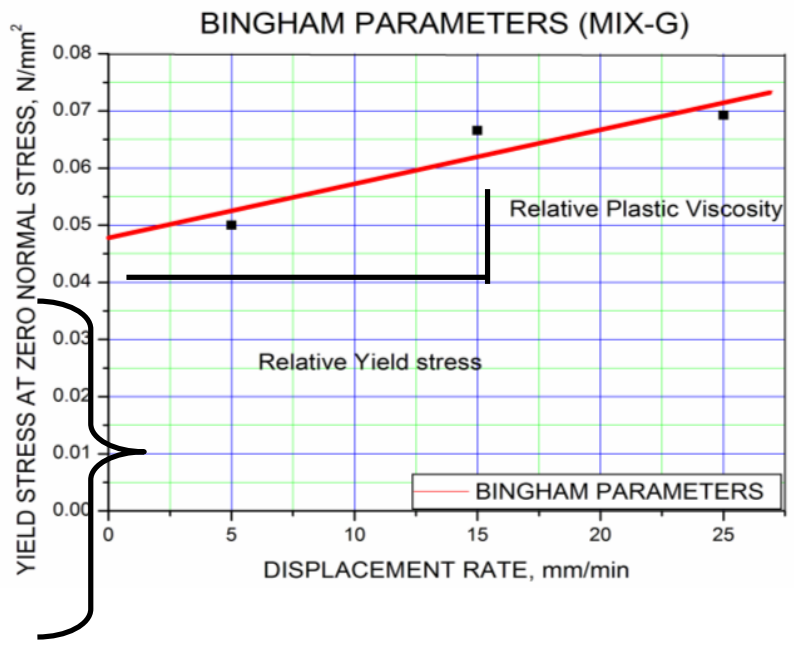

Figure 4 : Yield Stress at Zero Normal Stress Vs Displacement Rate

Table 1: Peak Shear Stress for Different Normal Stresses and Displacement Rates

\begin{tabular}{|c|c|c|c|c|c|c|c|c|c|c|}
\hline \multirow{2}{*}{$\begin{array}{l}\text { Normal } \\
\text { Stress } \\
\text { MPa }\end{array}$} & \multirow{2}{*}{$\begin{array}{c}\text { Disp. } \\
\text { Rate } \\
\mathrm{mm} / \mathrm{min}\end{array}$} & \multicolumn{9}{|c|}{ Peak Shear Stress (MPa) } \\
\hline & & Mix-A & Mix-B & Mix-C & Mix-D & Mix-E & Mix-F & Mix-G & Mix-H & Mix-I \\
\hline \multirow{3}{*}{0.015} & 5 & 0.09800 & 0.10444 & 0.06900 & 0.09911 & 0.82466 & 0.08456 & 0.07346 & 0.08450 & 0.08144 \\
\hline & 15 & 0.10888 & 0.11888 & 0.09485 & 0.11988 & 0.11888 & 0.09366 & 0.08987 & 0.10986 & 0.07968 \\
\hline & 25 & 0.12866 & 0.12777 & 0.09698 & 0.13899 & 0.11033 & 0.09452 & 0.08765 & 0.08457 & 0.10597 \\
\hline \multirow{3}{*}{0.025} & 5 & 0.12977 & 0.10955 & 0.13452 & 0.13322 & 0.12899 & 0.10687 & 0.12752 & 0.13345 & 0.13345 \\
\hline & 15 & 0.14555 & 0.20444 & 0.12650 & 0.13936 & 0.19685 & 0.16466 & 0.14245 & 0.16845 & 0.14584 \\
\hline & 25 & 0.15888 & 0.19865 & 0.12548 & 0.20945 & 0.13456 & 0.13964 & 0.16234 & 0.19345 & 0.11864 \\
\hline \multirow{3}{*}{0.035} & 5 & 0.14985 & 0.14735 & 0.14644 & 0.15644 & 0.13856 & 0.14650 & 0.14649 & 0.18649 & 0.15468 \\
\hline & 15 & 0.16104 & 0.21658 & 0.14540 & 0.16146 & 0.19346 & 0.16999 & 0.10514 & 0.13345 & 0.12476 \\
\hline & 25 & 0.17485 & 0.14256 & 0.11530 & 0.23522 & 0.15924 & 0.15654 & 0.12233 & 0.15168 & 0.12148 \\
\hline
\end{tabular}


Table 2: Relative Yield Stress and Relative Plastic Viscosity (with and without Chemical Admixture)

\begin{tabular}{|c|c|c|c|c|c|c|c|c|}
\hline \multirow{2}{*}{ Mix } & \multirow{2}{*}{$\begin{array}{l}\text { Cement } \\
\left(\mathrm{kg} / \mathrm{m}^{3}\right)\end{array}$} & \multirow{2}{*}{$\begin{array}{l}\text { Water } \\
\left(1 / \mathrm{m}^{3}\right)\end{array}$} & \multirow{2}{*}{$\begin{array}{c}\text { Fine } \\
\text { Aggregate } \\
\left(\mathrm{kg} / \mathrm{m}^{3}\right)\end{array}$} & \multirow{2}{*}{$\begin{array}{c}\text { Coarse } \\
\text { Aggregate } \\
\left(\mathrm{kg} / \mathrm{m}^{3}\right)\end{array}$} & \multicolumn{2}{|c|}{ Relative yield stress $(\mathrm{Pa})$} & \multicolumn{2}{|c|}{$\begin{array}{l}\text { Relative Plastic Viscosity } \\
\text { (MPa-s) }\end{array}$} \\
\hline & & & & & $\begin{array}{c}\text { Without } \\
\text { chemical } \\
\text { admixture }\end{array}$ & $\begin{array}{c}\text { With } \\
\text { chemical } \\
\text { admixture }\end{array}$ & $\begin{array}{l}\text { Without } \\
\text { chemical } \\
\text { admixture }\end{array}$ & $\begin{array}{c}\text { With } \\
\text { chemical } \\
\text { admixture }\end{array}$ \\
\hline A & 300 & \multirow{3}{*}{160} & 795 & 1184 & 80800 & 54917 & 2.75 & 11.52 \\
\hline B & 390 & & 765 & 1139 & 75400 & 31381 & 3.15 & 25.92 \\
\hline $\mathrm{C}$ & 450 & & 745 & 1108 & 44900 & 13729 & 4.07 & 26.64 \\
\hline $\mathrm{D}$ & 300 & \multirow{3}{*}{175} & 780 & 1160 & 50995 & 44129 & 4.68 & 13.21 \\
\hline E & 390 & & 749 & 1115 & 30401 & 24222 & 6.48 & 26.21 \\
\hline $\mathrm{F}$ & 450 & & 729 & 1085 & 25497 & 17357 & 13.68 & 29.51 \\
\hline $\mathrm{G}$ & 300 & \multirow{3}{*}{190} & 764 & 1136 & 40800 & 23535 & 12.31 & 25.20 \\
\hline $\mathrm{H}$ & 390 & & 733 & 1091 & 26459 & 20593 & 27.72 & 27.72 \\
\hline I & 450 & & 713 & 1060 & 23323 & 18632 & 25.27 & 33.84 \\
\hline
\end{tabular}

Table 1 shows the peak shear stress values for all the mixes without the addition of chemical admixture, for different normal stresses and displacement rates. It can be observed from the results that as the normal stress increased for the same mix with a particular displacement rate, the peak shear stress also increased. This could be because as the normal stress is increased the particle gets closer to each other thereby causing the interlocking of the aggregates leading to higher resistance resulting in higher peak values. This is true for all the mixes and displacement rates. Also, for a particular normal stress generally the peak shear stress increased as the displacement rate increased. This could be due to the reason that when the displacement rate is lower there is more time available for the effect of particle re-orientation in the test resulting in lower peak values. It is likely that the displacement rates influence the Bingham parameters and can be one of the factors influencing the results.

Table 2 shows the relative yield stress and relative plastic viscosity along with the mixture proportions of the mixes with and without using the chemical admixture. In this study the yield stress and the plastic viscosity values were called as relative yield stress and relative plastic viscosity because the values are not absolute. From Table 2 it can be observed that in a given mix for the same water content as the cement content increased the relative yield stress of concrete decreased. This phenomenon is attributed to higher paste content (cement + water). As the cement content is increased for the same water content it results in higher volume of paste and better lubrication of the aggregate particles thereby reducing the inter-particle friction and also probably due to better coating of the paste on the aggregates. Also higher paste content means lower aggregate content and lower volume fraction of aggregates result in increased spacing between aggregates and thus lesser resistance to flow. This is also true when the water content is increased for the same cement content. As such at lower paste content the interparticle friction dominates resulting in higher relative yield stress which is clearly brought out by the concrete shear box test.
Similarly, the relative plastic viscosity values are higher for the same water content with higher cement content as the mix becomes more cohesive. An increase in the cement content at constant water/cement ratio provides more paste to coat aggregates and to fill the spaces between the aggregates. These observations are also true for the mixes with chemical admixture. The reduction of relative yield stress is more predominant for all the mixes with different water contents. In general, use of high range water reducing admixtures results in decrease in yield stress and plastic viscosity.

Relative yield stress and relative plastic viscosity obtained in this study are higher than those reported in the literature using rheometers. This could be possibly due to particle interference or friction during shearing at low rates. In most rheometer experiments, initially the fresh concrete is sheared at high rate before the rheological tests and then the shear rate is reduced gradually in order to obtain the Bingham curve [2]. Such high shear rates are normally not encountered while placing of concrete. But the trends reported are similar to the results obtained using rheometers i.e., higher the paste content the lower the yield stress [6].

\section{CONCLUSION}

This experimental study has shown that the specially fabricated concrete shear box can be used to find the Bingham parameters of fresh concrete. The test is unique in the sense that the results are consistent and the values arrived at, are by considering both the normal stress and displacement rate at zero values and the stimulus provided to the concrete is similar to the field practice. The Bingham parameters are named as relative yield stress and relative plastic viscosity partly because the values so obtained are higher than those reported in literature as determined by high shear rate rheometers. For the same mix, as cement content increased there is a significant reduction in relative yield stress or in general as the paste content increased there is also significant decrease in the relative yield stress of concrete or increase in 
relative plastic viscosity. This aspect may be useful in identifying the intrinsic changes in the mixes for the volume of paste or changes in the grading of aggregate for a given paste content. The concrete shear box can be used as a tool to determine Bingham parameters effectively as a static test by following the unique procedure developed in place of rheometers which use high shear rate.

\section{REFERENCES}

[1] C. Ferraris and L. Brower, eds., "Comparison of Concrete Rheometers": International Tests at MB (Cleveland OH, USA) October 2000, National Institute of Standards and Technology NISTIR 7154, 2001.

[2] Koehler, P. Eric and Fowler, W. David, "Development of a Portable rheometer for fresh Portland cement concrete", ICAR Report 105-3F, 2004.

[3] Q.D. Nguyen and D.V. Boger, "Yield stress measurement for concentrated suspensions", Journal of Rheology, Vol. 27, No. 4, Pp 321349, 1983.

[4] P.F.G. Banfill, (), "The rheology of fresh cement and concrete-A review" 11th international Cement Chemistry Congress, Durban, 2003.

[5] V. Hackley and C.F. Ferraris, () "The Use of Nomenclature in Dispersion Science and Technology", (Special Report 960-3). Gaithersburg, MD: National Institute of Standards and Technology, 2001.

[6] Ferraris, F. Chiara., and Brower, Lynn E., "Comparison of concrete rheometers" Concrete International, Vol.25, No.8, Pp 41-47, 2003.

[7] K. Newman, Concrete systems, In: Holliday, L.,(ed.), Composite materials, Amsterdam, Elsevier, Publishing co Ltd., Pp 335-452, 1966.

[8] S. Girish, C. Indumathi, Jagadish Vengala and R.V. Ranganath, "Rheological Properties of Self-Compacting Concrete using Direct Shear Box", The Indian Concrete Journal, Vol. 83, No. 8, Pp 47-53, 2009.

[9] S. Girish and B.S. Santhosh, "A new methodology to study the rheological properties of fresh Portland cement concrete", International Journal of Earth Sciences and Engineering", Vol. 04, No. 06, SPL, Pp. 797-800, 2011

[10] S. Girish and B.S. Santhosh, G.S Vinay Kumar, L. Shobha "Rheological Measurement of Fresh Portland Cement Concrete Using Direct Shear Box Tests, Proceedings of the International Conference "Concrete in the Low Carbon Era" University of Dundee, Scotland, UK, Pp. 287-302, 2012.

[11] Ferraris, F. Chiara, "Measurement of the rheological properties of high performance concrete: state of the art report", Journal of research of the national institute of standards and technology, Vol. 104, No. 5, Pp 461478, 1999.

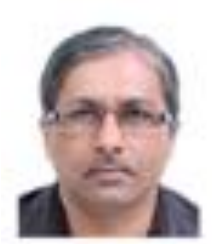

Dr.S. Girish has 25 years of experience in teaching, consultancy and research and is presently working as Professor in the Department of Civil Engineering, B.M.S College of Engineering (BMSCE), Bangalore, Karnataka, India. He has worked on Self- compacting concrete for his doctoral work and has published research papers in various National and International Journals and in Conferences and was the recipient of Karnataka State Council for Science and Technology Academic award for the best project in the year 2009 and 2011. He is guiding 4 research scholars for doctoral work. He is member in various professional societies including Indian Society for Technical Education, The Indian Concrete Institute, Institution of Engineers (India), Indian Society for Earth quake resistant Structures.

His research interests include Self-compacting concrete, Rheology of concrete, Recycling of concrete waste, Bacterial concrete, Pervious concrete and Geopolymer concrete. (E-mail: giris41@yahoo.co.in and girish.civ@bmsce.ac.in )

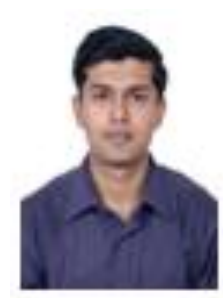

B.S. Santhosh, is pursuing his doctoral work on rheological properties of fresh concrete using concrete shear box. Presently he is a Assistant Professor in the Department of Civil Engineering, JSS Academy of Technology Education, Bangalore. He has obtained his Master of Technology (M.Tech.) in Structural Engineering from M S Ramaiah Institute of Technology (MSRIT), from VTU Belgaum, Karnataka, India in 2010 and Bachelor of Engineering (B.E.,) in Civil Engineering, from University Visvesvaraya college of Engineering, Bangalore University, Bangalore, Karnataka, India, in 2007.

His areas of interest include SCC, Pervious concrete and Rehabilitation of Structures. He has published research papers in International Journal and in Conferences (E-mail: santhoshbss@gmail.com) 